\title{
"It's not just your dad and it's not just your coach..." The dual-role relationship in female tennis players
}

\author{
Olivier N. Schmid
}

Follow this and additional works at: https://researchrepository.wvu.edu/etd

\section{Recommended Citation}

Schmid, Olivier N., "'It's not just your dad and it's not just your coach..." The dual-role relationship in female tennis players" (2014). Graduate Theses, Dissertations, and Problem Reports. 7345.

https://researchrepository.wvu.edu/etd/7345

This Dissertation is protected by copyright and/or related rights. It has been brought to you by the The Research Repository @ WVU with permission from the rights-holder(s). You are free to use this Dissertation in any way that is permitted by the copyright and related rights legislation that applies to your use. For other uses you must obtain permission from the rights-holder(s) directly, unless additional rights are indicated by a Creative Commons license in the record and/ or on the work itself. This Dissertation has been accepted for inclusion in WVU Graduate Theses, Dissertations, and Problem Reports collection by an authorized administrator of The Research Repository @ WVU.

For more information, please contact researchrepository@mail.wvu.edu. 
"It's not just your dad and it's not just your coach..."

The dual-role relationship in female tennis players

Olivier N. Schmid

Dissertation submitted to the College of Physical Activity and Sport Sciences at West Virginia University in partial fulfillment of the requirements for the degree of

Doctorate of Philosophy: Sport and Exercise Psychology

Samuel Zizzi, Ed.D., Chair

Malayna Bernstein, Ph.D.

Kristen Dieffenbach, Ph.D.

Alfred Kasprowicz, Ph.D.

Jack Watson, Ph.D.

Morgantown, West Virginia

January, 72014

Keywords: parent-coach, dual-role relationship, tennis, abuse 
UMI Number: 3618397

All rights reserved

INFORMATION TO ALL USERS

The quality of this reproduction is dependent upon the quality of the copy submitted.

In the unlikely event that the author did not send a complete manuscript and there are missing pages, these will be noted. Also, if material had to be removed, a note will indicate the deletion.

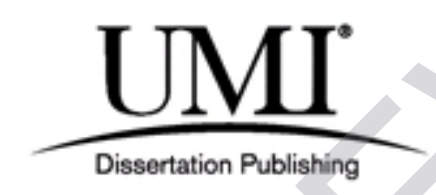

UMI 3618397

Published by ProQuest LLC (2014). Copyright in the Dissertation held by the Author.

Microform Edition (c) ProQuest LLC.

All rights reserved. This work is protected against unauthorized copying under Title 17, United States Code

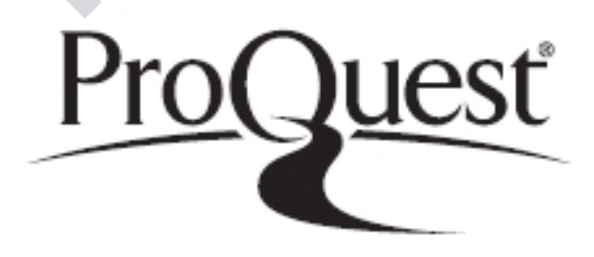

ProQuest LLC.

789 East Eisenhower Parkway

P.O. Box 1346

Ann Arbor, MI 48106 - 1346 


\author{
ABSTRACT \\ "It's not just your dad, it's not just your coach..." \\ The dual-role relationship in female tennis players \\ Olivier N. Schmid
}

Parents and coaches were encouraged to keep their roles separate in order to promote optimal youth sport participation and avoid excessive and pressuring involvement (Gould, et al., 2008; Wolfenden \& Hoyt, 2005). Despite these recommendations, the phenomenon of parents volunteering to coach their own children has dramatically increased (Brown, 1998).

Managing the blurred boundaries of these coaching dual-role relationships throughout the athlete's development is a delicate endeavor and remains unexplored in individual sports (Jowett, 2008; Weiss \& Fretwell, 2005). Tennis has been identified as an ideal context to examine the dynamics of parenting and coaching relationships and is notorious for a high prevalence of parent-coaches (Agassi, 2009; Gould et al., 2008; Lauer, 2010). The purpose of this study was to examine the experiences of female tennis players who were coached by their fathers since childhood and then competed for an NCAA Division I college tennis team. All 318 NCAA Division I women's tennis coaches were contacted and a purposive sampling method was used to identify eight eligible female tennis players willing to participate. A phenomenological interview approach was used to examine their experiences with the dualrole relationships and coaching transitions to college. A holistic narrative approach was used to build the trajectories of these relationships retrospectively. Findings were displayed following the four developmental periods where specific challenges emerged. Navigating the blurred boundaries was negatively influenced, to various degrees, by the participants' dependency and urges to receive approval from their fathers, the presence of physical and emotional abuse, the lack of conflict resolution strategies, and the strain on family members. The coaching transitions helped normalize the father-daughter relationships and provided insight into the respective needs that were fulfilled through the dual-role relationships. One particular father-daughter dyad suggests that such relationships are not impossible to manage successfully and recommendations for parent-coaches are offered. 


\section{ACKNOWLEDGEMENTS}

Enjoying my journey at West Virginia University and achieving this project successfully could not have happened without the ongoing support of several individuals who I have felt so privileged to have around me.

Foremost, I would like to express my sincere gratitude to each of my committee members. My goal was to form an eclectic committee including a unique blend of expertise, talents, and personalities. I felt blessed that all of you accepted right away. You were highly invested in ensuring the quality of this project and so generous with your time, thoughtfulness, and support. I could not have hoped for a more pleasant and smooth experience.

Dr. Sam Zizzi, you accepted to take over the chair of this dissertation along the way... via email, within 20 minutes, and on a Friday night! The ultimate honor. Since then, you offered me your unconditional support and every possible opportunity to emerge from the cave and achieve this project successfully. Over the past five years, your trust and close mentoring helped me grow far beyond my academic responsibilities and venture on the middle path. You have been much more than an advisor and there is no doubt that I will keep learning from you and that our bonds will keep growing despite the distance.

Dr. Malayna Bernstein, you stepped up when I needed you the most and never lost your enthusiasm and creativity during our numerous meetings. I wish this final product could be close to match the quality of the guidance and insights you offered me over the past two years! Throughout the entire process, you were always in tune with where I was at, without ever imposing your views. You enriched my understanding of qualitative research and helped me develop my own research conceptualizations. The opportunity to work with you was a privilege and a lot of fun!

Dr. Kristen Dieffenbach, thank you for brainstorming the idea of investigating dualrole relationships in tennis during a random hallway conversation! Having you on my committee was a no brainer and I am grateful for always leaving our meetings feeling inspired, excited, and yet challenged to ponder so many thoughtful perspectives on long-term athlete development and on coaching and parenting education. You always looked out for me and helped me build professional connections in the field since the very beginning. I look forward to collaborating with you on new projects soon!

Dr. Al Kasprowicz, I feel blessed that you accepted to take on the additional responsibility to be part of this project with such enthusiasm. Over the years, the quality of the supervision and guidance you offered me in a variety of contexts was outstanding. Any meeting with you has always been a mind-blowing experience, to the point that I still try to wrap my head around some of the insights I gained. You will remain a role model for me and your eloquence and sense of perspective will always be a source of inspiration.

Dr. Jack Watson, your guidance and commitment throughout these four years at WVU were not limited to this project and I am grateful for your positivity and all the resources you made available for me. In tricky situations, you trusted and offered me opportunities to make my own informed decisions. Your support along the different phases of my academic journey have helped me gain confidence in my ability to succeed in the field... and on the golf course! 
Dr. Vanessa Shannon, I am grateful for all the time and energy you invested in helping me launch this project. I would not have achieved it without your "pretty good" insights and tips on thorough research writing. It was a challenging time to see you leave WVU, but I am very thankful for your mentoring.

A special thank you to Carrie Rishell and Tina Griffith for your patience and the generous efforts you put into the coding of each interview. I truly valued your perspectives and you made the data analysis a fun process. I am also thankful for my roommate Christine Yurko, for all your remarkable and timely proofreading help. You always made yourself available despite tight deadlines.

Of course, this dissertation would not have come to light without the participation of the female tennis players I had the privilege to interview and get to know. I have been so appreciative for your patience, openness, and willingness to share with me all your stories and experiences, through joy and tears. Whether your narratives were included in this dissertation or will be part of a subsequent manuscript, you can be sure that your insights, perspectives, and recommendations are highly valued and will help other players, parent-coaches, and their family members.

To all my friends and classmates at WVU who made this program so unique and to the best cohort I could possibly dream of having over the last four years. May the spirit of Yari and FYD॰ stay with us.

I would not have achieved this dissertation without receiving the ongoing support from several close friends, family members, and mentors in Morgantown, Springfield, and back home in Switzerland. During moments of doubts, you always supported me encouraged me to pursue my career path without ever questioning my ability to succeed.

Last but certainly not least, I address my deepest gratitude to Cathy Yura, Patrick Odier, and Jacques G. I cannot possibly express enough how much your unconditional support and positive regard have meant to me. These few words probably embarrassed your true sense of humility but I really need you to know that without you, I would simply not have made it to the end of my PhD. 
DEDICATIONS

To my close friend Nanaxhi Chavez from Mexico, whose tennis experience contributed to inspire this research.

To my mom and dad. 
Introduction 1

Limitations of Previous Research 9

Research Questions and Assumptions 11

$\begin{array}{ll}\text { Method } & 11\end{array}$

Research Design and Paradigm 11

$\begin{array}{lr}\text { Sampling } & 12\end{array}$

Participants $\quad 13$

Data Collection Procedures 13

Data Analysis $\quad 16$

$\begin{array}{ll}\text { Trustworthiness } & 17\end{array}$

Findings $\quad 18$

Demographics $\quad 18$

Organizational structure of findings $\quad 18$

A. Dynamics of the dual-role relationships 19

B. Individuation process $\quad 33$

C. Transition to College Tenis 35

Discussion $\quad 43$

Abusive dual-role relationship in tennis 44

Blurred boundaries and lack of communication 46

Dependency and the individuation process 47

Satisfying the respective needs 49

Tennis as a context for father-daughter relationship $\quad \mathbf{5 0}$

Practical implications $\quad 53$

Limitations $\quad 55$

$\begin{array}{ll}\text { Suggestions for future research } & 57\end{array}$

$\begin{array}{ll}\text { References } & 58\end{array}$

Table 1: Demographics of participants, father-coaches, $\mathbf{6 6}$

and college coaches.

$\begin{array}{ll}\text { Figure 1: Cross-case time ordered matrix: specific issues and } & \mathbf{6 7}\end{array}$

Appendix A: Online Survey for participants' recruitment $\quad 68$

Appendix B: Coach recruitment email $\quad 70$

Appendix C: Participant cover letter (online survey) 71

Appendix D: Participant cover letter (interview) 72

Appendix E: Expanded Review of Literature $\quad 73$

$\begin{array}{ll}\text { Youth Sports Participation } & \mathbf{7 3}\end{array}$

Positive youth development through sport $\quad 73$

Developmental needs of youth athletes $\quad 74$

Adults Involvement in Youth Sports $\quad 84$

Facilitating an optimal motivational climate $\quad 86$

$\begin{array}{ll}\text { Coaching in youth sports } & 87\end{array}$

The impact of parenting styles on children's behavior 88

Outcomes of parental involvement on youth athletes 92 
Parenting youth athletes in tennis

The Parent-Coach Child-Athlete Dual-Relationship 99

Definitions and implications 99

Origin and challenges $\quad 101$

Benefits and concerns 103

Challenges during adolescence $\quad 107$

Recommendations 110

Transitioning out of a coaching dual-relationship 111

References 112 


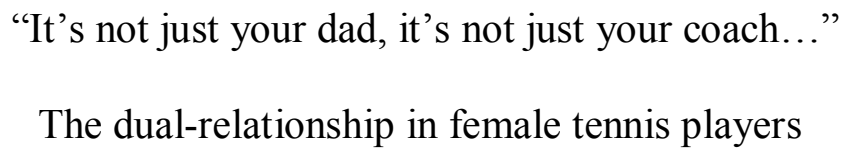

\section{Introduction}

Youth sport participation has been identified as an ideal context for the acquisition of athletic competence and for the development of transferrable life skills that can be applied to other important areas of life (e.g. Danish, Petitpas, \& Hale, 1990; Weiss \& Smith, 2002). Even though the acquisition of such skills is highly beneficial for the physical and psychosocial development of youth athletes, enjoying a positive athletic experience and the process of learning and transferring life skills do not occur by default, with mere sport participation. In order to foster positive youth development through sport, coaches, parents, and mentors must intentionally provide athletes with an optimal learning environment.

Substantial effort continues to be invested to investigate the critical roles of coaches and parents who influence the sport participation of the 30 to 45 million of youth athletes in

the United States (Ewing \& Seefeldt, 2002; Fredricks \& Eccles, 2004; Horn, 2002; Minnesota Amateur Sports Commission, 2012). The population of adults and parents who volunteer to coach has increased to meet the coaching needs of youth athletes, but the level of competence of these adults for coaching children and adolescents can be limited and not ideal (Wiersma $\&$ Sherman, 2005). Because youth sport participation and coaching education are not institutionalized by a central governing organization in the US, the requirements for minimal coaching competence vary greatly across sports, depending on the standards set by the respective national governing bodies.

Despite the lack of national coaching standards across all sports, experts in athletic talent development have emphasized that children should not be treated like "miniature adults" (Danish et al., 1990, p. 171) and have set recommendations so that parents and coaches can meet the unique needs of athletes, from childhood to late adolescence (e.g. 
Bloom, 1985; Côté, 1999; Wolfenden \& Holt, 2005). Based on Erikson's stages of psychosocial development (1959), during childhood and early adolescence (until 12-13 years old; Wylleman \& Lavallee, 2004) children strive to develop a sense of industry (by opposition to inferiority) through experiencing success and gaining self-efficacy. Upon achievement of this development task, the stage of late adolescence (13-18 years old) is characterized by the need to form a sense of personal identity, through individuation and separation from early parental identification. During this stage, adolescents explore different types of activities (e.g. beyond their own sport) and transfer their dependence and emotional attachment from their parents to role models and peers from various backgrounds. Through these experiences, adolescents have the opportunity to learn about themselves, gain perspective, make informed decisions, develop coping strategies (e.g. self-regulation and confidence), and foster personal growth (Petitpas \& France, 2012). Research investigations on National Collegiate Athletic Association (NCAA) student-athletes suggests that overcommitting to one's sport as a way to gain a sense of self-worth and identity can lead to identity foreclosure (Hansen \& Sackett, 1993; Marcia, 1966; Miller \& Kerr, 2003). As a result, failure to engage in exploratory activities and to develop autonomy from parental authority can delay, and even prevent, the process of career exploration by selecting a career path that is incongruent with their competences, interests, and values.

Research on parenting in sport indicates that the degree of parental involvement can impact the level of stress experienced by youth athletes (Fredrick \& Eccles, 2004; Hellstedt, 1987). The level and quality of parental involvement was inherently found to be either positive or negative because it primarily depends on the children's interpretations of their parents' behaviors and attitudes (Kanters, Bocarro, \& Casper, 2008). Moderate levels of parental involvement was perceived as the most supportive and conducive to positive youth 
sport development (Wuerth, Lee, \& Alfermann, 2004), but finding the right balance of involvement has remained a challenging endeavor for parents.

According to the different stages of talent development, parental involvement should ideally be higher during the early phase, whereas coaches should become more active role during the specialization stage (e.g. Wolfenden \& Holt, 2005). In reality, the western societal norms for successful achievement often lead coaches and parents to overly focus on winning and high intensity training prematurely (Coakley, 2009). High and unrealistic expectations to perform can interfere with the phases of talent development and lead athletes to experience elevated stress, injuries, and burnout. Youth sport attrition has been explained by factors inherent to the lack of interest in the sport itself, but has mainly been attributed to poor coaching and parenting behaviors (Seefeldt, Ewing, \& Walk, 1992). In addition to the loss of psychosocial benefits, discontinued sport participation has been associated with the onset of chronic diseases related to physical inactivity (Center for Disease Control, 2010; Woods et al., 2010).

Despite these consequences related to adults' inadequate involvement in youth sport, parents and coaches have the potential to foster the psychosocial and athletic development of athletes and to promote lifetime physical activity (Coatsworth \& Conroy, 2006; Fredricks \& Eccles, 2004). Optimal parenting and coaching includes a balance between challenging and supportive behaviors that are congruent with the developmental needs and skill level of the athletes (Côté, Baker, \& Abernethy, 2003; Gould, Dieffenbach, \& Moffett, 2002; Larson, 2006). To facilitate positive development, the literature on coaching effectiveness from both athletic and psychosocial perspectives has emphasized the benefits of building harmonious coach-athlete relationships, promoting a mastery motivational climate, and positively reinforcing desirable behaviors and attitudes in order to increase athletes' enjoyment, selfesteem, intrinsic motivation, and continued participation (DiCicco \& Hacker, 2002; Duda \& 
Hall, 2001; Halliburton \& Weiss, 2002; Smoll, Smith, Barnett, \& Everett, 1993; Wolfenden \& Holt, 2005).

In contrast, the inappropriate behaviors of coaches and parents typically reflect the outcome orientation endorsed by certain adults, intentionally or unknowingly, at the expense of physical or emotional abuse (Agassi, 2009; Stirling, 2013; Stirling \& Kerr, 2013). In the sport setting, emotional abuse was documented as the most frequent form of abuse within coach-athlete relationships (Kirby, Greaves, \& Hankivsky, 2000) and was defined as a "pattern of deliberate non-contact behaviours within a critical relationship that has the potential to be harmful" (Stirling \& Kerr, 2008, p. 178). Emotional abuse includes physical behaviors (e.g. throwing objects or equipment and punching walls to intimidate), verbal behaviors (e.g. demeaning and humiliating comments privately or in public, threat, namecalling and swearing at the athlete), and the denial of attention and support (e.g. intentionally ignoring the athlete's needs and providing inadequate feedback). Emotional abuse was further categorized as expressive and instrumental in nature (Stirling, 2013). Expressive emotional abuse is characterized by the use of abusive behaviors out of anger or frustration (e.g. yelling demeaning statements or insults), whereas instrumental emotional abusive behaviors are used as means to achieve an end (e.g. punishment for the "benefit" of talent development). Emotional abuse during childhood was found to have a detrimental impact on the well-being and long-term development of children, including mental health (e.g. low selfesteem, poor body image, depression, anxiety) and psychosocial issues (Jellen, McCarroll, \& Thayer, 2001; Stirling \& Kerr, 2013).

When examining coaching and parenting practices in youth sport, tennis has often served as an ideal setting because athletes can attain elite levels at an early age and parental involvement is necessary due to the individual and costly nature of the sport (Gould, et al., 2008). Although tennis coaches and parents were found to be well-intentioned, their 
involvement in tennis was often reported as excessive, negative, and pressuring. The consequences of a lack of realistic expectations and effective collaboration between coaches, parents, and athletes, may go far beyond the sport environment and impact the parent-child relationship and the family system. Researchers recommended that coaches and parents adopt specific and different roles in order to provide an optimal experience for youth tennis players (Gould, et al., 2008; Wolfenden \& Hoyt, 2005).

Despite these recommendations, the estimated number of parents volunteering to coach their own children has grown from $58 \%$ in 1979 to almost $90 \%$ in 1998 across all sports in the United States (Brown, 1998; Gould \& Martens, 1979). However, accurate and current demographic data regarding the prevalence of parent-coaches are lacking. In tennis, numerous professional female (e.g. Marion Bartoli, Jennifer Capriati, Serena and Venus Williams, Martina Hingis) and male (e.g. Andre Agassi, Andy Murray) players were coached by a parent during the course of their career. Several of these highly successful tennis athletes were also the victims of inappropriate or abusive behaviors from their parent-coaches (Agassi, 2009; Jordan, 1993; Moore 2006). Even though some cases of physical abuse have been reported at the junior tennis level, the prevalence of abuse still remains unknown within the context of dual-role relationships (DeFrancesco \& Johnson, 1997). It is likely that the cases of tennis players who were coached by a parent and have been less successful on the court tend to naturally be underreported because they did not make it to the top. Marion Bartoli's decision to retire from professional tennis at age 28 and less than six weeks after her recent win at Wimbledon elicited the media's curiosity regarding the history of her dual-role coaching relationship, which was commonly described as tumultuous (Briggs, 2013; Mole, 2013). In the youth sport literature, the parent-coach phenomenon has not been explored in depth and is lacking in tennis (Jowett, 2008). 
A parallel can be drawn between early research on the concept of familial coaching relationship (or coaching dual-relationship) where the parent is also the coach and the ethical recommendations for practitioners in the field of psychology (Kitchener, 1988). Therapists have been warned against engaging in any parallel relationships with their clients in order to limit the potential for role confusion and conflict of interest that might interfere with the therapeutic process and possibly harm or exploit clients. Applied to the sport setting, a coaching dual-relationship also has the potential to lead to role conflict and conflict of interests (Secord \& Backman, 1974). Role conflict can occur when the coaching and parenting roles are incompatible, such as when the coaching role warrants to challenge an athlete's physical and psychological limits while the parenting role simultaneously strives to provide unconditional support and protection. Conflicts of interests may occur when parentcoaches prioritize their own needs for success, prestige, or authority at the expense of the child's psychosocial and developmental needs (Kitchener, 1988).

In contrast, the dual-role relationship can be beneficial because parents and athletes already know each other well (Weiss \& Fretwell, 2005) and children enjoyed receiving special attention and praise from their parent who was seen as a source of motivation. However, the boundaries between the parenting and coaching roles are inherently blurred. As a result, negative feelings experienced in the parenting or coaching context are more likely to impact the family and sport contexts (Jowett, 2008; Weiss \& Fretwell, 2005) when compared to traditional coach-athlete relationships.

Findings on how coaching dual-relationships are formed were succinct and suggest that the child's needs for positive development were not necessarily of primary concern for parent-coaches (Evans, 1985; Jowett, 2008; McCaan, 2005; Weiss \& Fretwell, 2005). The main purpose of early research on the coaching dual-relationship was to explore the difficulty in keeping the coaching and parenting roles separate and the impact of the dual-relationship 
on both parent-coaches and child-athletes (Evans, 1985; Weiss \& Fretwell, 2005). Coaching dual-relationships ultimately have the potential to damage the parent-child relationship far beyond the athletic environment. From childhood to early adolescence, children's relationships needs include the importance to please and receive praise and positive feedback from their parents. Towards late adolescence, youth needs more autonomy from their parents, which can become complex in instances when the parents are also the coaches. Also, the coaching relationship was perceived by children as an opportunity to solidify the bonds through shared interest and mutual respect.

Parent-coaches reported that knowing their athlete better than anyone else and having higher quality of interactions was particularly appealing (Weiss \& Fretwell, 2005). A coaching dual-relationship where the experience of both members was congruent and positive was labeled a cordial relationship. Despite these benefits, the coaching dual-relationship also included a series of issues and discrepancies between parent-coaches and their children, which was categorized as a contentious relationship. Common issues reported by childathletes were attributed to being exposed to a higher level of pressure and expectations than their teammates, feeling controlled, and the difficulty to accept critical feedback as an athlete from a coach and not from a parent (Weiss \& Fretwell, 2005). As a result, the stress experienced within the coaching dual-relationship could impact children's level of functioning in other life areas and alter the parent-child relationship. Parent-coaches reported difficulties in treating their children fairly and were found to either favor or discriminate against their child more than others as to avoid misperceptions and rumors from teammates and their parents (Jowett, 2008).

In addition to these concerns related to differential treatments, research consistently suggests that role conflict is one of the most challenging issues, since both parent-coaches and child-athletes reported the difficulty to keep the coaching and parenting role separate 
(Evans, 1985; Jowett \& Meek, 2000; McCann, 2005; Weiss \& Fretwell, 2005). During adolescence, role conflict was reported as particularly delicate to handle for both members of the relationship, because children are in quest of individuation from their parents and engaged in solving a variety of psychosocial development tasks away from the family system (Erickson, 1959). Indeed, receiving coaching advice from a parent appeared to be undesirable for teenage athletes unless they requested the feedback (McCann, 2005). For parent-coaches, this period can be difficult to handle because while the parenting role is supposed to become less actively involved in the athletic experience of their child, the coaching role requires them to remain the primary source of coaching feedback (Bloom, 1985; McCann, 2005; Wylleman \& Lavallee, 2004). Gender differences regarding preferences for feedback and leadership styles were also found to increase the challenging period of adolescence (McCann, 2005). Encouragement and technical feedback provided by father-coaches after an error was not positively received by daughters. They typically interpreted praise as a sign of lack of competence, which made the task of father-coaches even more complicated. A democratic leadership style and an authoritative parenting style (Baumrind, 1971, 1991) from father-coaches were preferred by female athletes from age 10 to 18 (McCann, 2005). In turn, such a coaching and parenting approach was found to facilitate role separation and mutual interactions in the coaching dual-relationship. Jowett (2008) suggested that interdependent relationships between parent-coaches and child-athletes, where each member of the relationship shared common interests and benefit mutually from the dual-relationship, could lead to harmonious interactions. Parent-coaches were encouraged to adopt a democratic coaching style and an authoritative parenting style in order to empower their children and foster autonomy, decision-making skills, and continued sport participation.

In addition to adopting an adequate parenting style, the main recommendations and ground rules for parent-coaches to promote a positive experience included the need for 
gaining self-awareness regarding their motives and needs for coaching their children and adopting specific behaviors and attitudes related to parents and coaching role. Furthermore, contracting, and monitoring expectations and emotional response while fostering open lines of communication and allowing feedback from their children were suggested in the literature (Jowett, 2008; Jowett, Timoson-Katchis, \& Adams, 2007; Lauer, 2008). The children's perception of parental involvement was found to be a major determinant of their sport participation, but investigations regarding the experiences and perceptions of youth athletes coached by a parent from childhood to adolescence is lacking in individual sports, like tennis (Harwood \& Knight, 2012).

\section{Limitations of Previous Research}

To date, research investigating dual-relationships between parent-coaches and childathletes was focused on swimming, soccer, baseball, basketball, and track and field (Jowett, 2008; Jowett et al., 2007; McCann, 2005; Weiss \& Fretwell, 2005). However, the understanding gained regarding how this dual-relationships were initially formed, evolved, and impacted the nature of the parent-child relationship once the child-athletes transitioned to another coach or discontinued their athletic careers remains widely unexplored. Although concerns related to favoritism or discrimination by parent-coaches are less likely to occur in individual sports like tennis (Lauer, 2008), the experience of tennis players may be unique and intensified within the context of individual lessons. In such a micro-environment, children coached by a parent do not have the ability to validate or gage their experience in comparison to other athletes. Similarly, parent-coaches may lack of perspective because they would not have access to feedback from other athletes and their parents. Tennis is a sport where players can experience loneliness because they are on their own most of the time when travelling to practice or competition (Agassi, 2009). Off the court, they have less opportunities for interacting with their age related peers and are surrounded by peers of 
different ages and adults. It is possible that social isolation and loneliness could be more intensified for tennis players who are coached by a parent.

An important methodological shortcoming of previous research conducted on dualrelationships includes the approach used to collect information when interviewing participants. Previous researchers have narrowed the scope of their investigations based on fundamental parenting and coaching principles, as well as, essential elements included in theories related to athletic talent development, role conflict, or competence motivation (Jowett, 2008; Jowett et al., 2007, McCann, 2005; Weiss \& Fretwell, 2005). Despite these promising findings and recommendations, to date, exploratory cases studies and open-ended interviews using a phenomenological approach are missing in dual-relationship research (Harwood \& Knight, 2012). Using a phenomenological approach could also allow to overcome the overly negative bias against parental behaviors that has been noticed by these two authors in a tennis parenting review of literature. Considering that the parent-coach child-athlete dual-relationship has never been explored strictly in an individual sport, the complexity and dynamics of this relationship remain unknown. Since children's selfperceptions, affect, and achievement motivation was found to be closely related to how children perceive their parents, the present investigation was specifically focused on the experiences of the daughter-athletes (Kanters et al., 2008). Furthermore, knowledge regarding how dual-role relationships started and retrospective longitudinal research examining the entire parent-coaches child-athletes collaborations and coaching transition are missing. The process and timing of when the father-coaches would need to let go of their coaching roles also remain unknown. The purpose of this research is to expand on previous research by examining the development and underlying dynamics of dual-role relationships learn how the transition process to college tennis operates. Practical recommendations for parent-coaches, tennis players coached by a parent, and NCAA college coaches are provided. 


\section{Research Questions and Assumptions}

The study sought to answer the following research questions: 1) How do female tennis players who were coached by their fathers before joining an NCAA Division I tennis team perceive their experience with the coaching dual-relationship? and 2) How do female tennis players who were coached by their fathers perceive their experience with the transition from being coached by their fathers prior to their collegiate career to being coached by a different coach in college?

Based on previous research and anecdotal reports, the researcher is making the following assumptions: 1) The experience of female tennis players who were coached by their fathers is unique, 2) One collegiate athletic year provides enough time and experience for the participants to have an opinion regarding their experience with the transition to their collegiate coach, and 3) The risks for a negative experience in individual sports are heightened because the dynamics and emotional reactions in the relationship are more intense (Lauer, 2008).

\section{Method}

\section{Research Design and Paradigm}

An exploratory qualitative research design was used to gain an understanding of how female tennis players who were previously coached by their fathers before joining an NCAA Division I tennis team perceive their athletic and personal experiences. An existential phenomenological approach was used to interview and access the structure and meaning of both the cognitive and emotional experiences of these female athletes (Moustakas, 1994). Phenomenological interviewing in qualitative research has its origin in philosophy and human sciences and was designed to describe the process by which individuals make sense of their inner world and individual experiences (Husserl, 1962). Phenomenology aligns with a constructivist paradigm, where it is assumed that the nature of reality does not exist per se, 
but can only be the product of an individual or collective construction process (Hatch, 2002). Within this perspective, the co-existence of multiple realities is acknowledged and unlike post-positivist paradigms, fully apprehending an absolute reality is a vain process. From an epistemological perspective, knowledge is not objective or absolute, but the result of a coconstruction through the lenses and the social interaction of both the primary investigator and the participants who are sharing their experiences, interpretations, and values. According to Mishler (1986), the researcher should not attempt to remain distant from the experience of the participants, but instead strive to collaborate with them on constructing a subjective reality that can be contrasted and agreed upon.

The process was data driven and not grounded in any pre-existing theories or used to validate any theoretical models. This methodology is ideal for exploratory research as it allows unanticipated topics to emerge from the research questions. However, after letting the data emerge from the interviews, the researchers remained open to the possibility that larger structures have shaped these experiences before the findings were put in perspective of the literature. Such models are lacking in the coaching dual-relationship literature and using a specific theory would limit the scope of the tennis players' experiences. Instead, the reality of these athletes' experiences is considered a form of abstract mental construction. The interview protocol only included one open-ended question, but an iterative approach was used to follow the lead of the participants and contextualize their experiences within existing theories. A narrative approach was used to retrospectively reconstruct and interpret the female athletes' experiences and life stories regarding their father-coaches and transition to college tennis.

\section{Sampling}

Purposive and snowball sampling methods were used to recruit eight female undergraduate student-athletes currently playing for National Collegiate Athletic Association 
(NCAA) Division I university women's tennis teams within the United States. Precedent for including NCAA Division I athletes was provided by Weiss and Fretwell (2005) who suggested that these athletes are likely to experience more significant concerns than athletes from less competitive backgrounds. The sample size matched, and in some instances, exceeded the number of athletes included in other qualitative studies examining the parentcoach child-athlete dual-relationship (Jowett, 2008; Weiss \& Fretwell, 2005).

\section{Participants}

All participants were over 18 years of age at the time of their interview. The interviewer was not related to nor had he interacted in any fashion with the participants prior to the interview. In previous research, the minimal duration of the father-coach daughterathlete relationship was determined as two continuous years (McCann; 2005). The eligibility criteria set for this study included that the collaboration between father-coaches and their daughters started before adolescence (before 13 years old, as defined by Wylleman \& Lavallee, 2004) and continuously until their transition to college. This criteria ensured that participants were coached by their fathers during adolescence, defined as a critical period when investigating coaching dual-relationship (Jowett et al., 2007; McCann, 2005). Additionally, all the participants had competed for at least one year at the college level, which ensured that they had experienced a full season of training and competition with their college coach after the coaching transition.

\section{Data Collection Procedures}

The study included two phases. Phase one served to identify and recruit collegiate female tennis players. Phase two served to interview eligible players who were willing to participate.

Phase I. During the 2012-2013 academic year, 320 women's tennis teams and 2,914 female tennis players competed at the NCAA Division I level (National Collegiate Athletic 
Association, 2013). After receiving approval from the Institutional Review Board (IRB), all NCAA Division I head $(n=318)$ and assistant $(n=210)$ coaches of women's tennis teams were contacted via their publicly available email address during the middle of their competitive season (spring semester). Two teams did not have any coaches and could therefore not be contacted. All head coaches and assistants coaches were asked to forward a request to their athletes regarding participation in an online survey regarding tennis players' transition to college. Those athletes who were willing to participate in the study found a cover letter informing them of their rights at the beginning of the online survey. Two reminders were sent to all these coaches one week apart.

The online survey was part of a larger study and designed to gather demographic characteristics related to the female tennis players and included age, race/ethnicity, major, cumulative Grade Point Average (GPA), age when they entered college, current year in college, and scholarship status. A question was included to determine whether or not the players have been previously coached by their fathers. If so, they were linked to a series of basic questions regarding that experience, including the age when their fathers started coaching them, the age when the father stopped coaching them, and any experience being coached by another coach other than their father prior to college in tennis. In addition to questions about themselves, participants were asked to answer several questions about their fathers, including age, race/ethnicity, current occupation, background as a player and as a coach in tennis and other sports, coaching certifications, main reason for coaching their daughters, and the nature of the satisfaction regarding his involvement, if any, in their daughter's current college tennis experience. The information garnered from this online survey was used to identify eligible participants for Phase II of the study.

Phase II. The sample for Phase II of the study was determined based on the number of participants matching the criteria for eligibility. At the end of the online survey, players 
who were previously coached by their father and who were willing to participate in an interview were asked to provide their contact information on a secure unlinked page. Out of the total of 147 female NCAA Division I tennis players who completed the survey, 50 (34\%) reported that they had been coached by their fathers in the past and 15 of them expressed interest in being interviewed regarding their experiences. Out of these 15 players, six did not meet all the inclusion criteria and three eventually opted out before being interviewed. As a result, six eligible participants were recruited from the online survey and two more participants were identified through snowball sampling. The sample for this study included a total of eight participants. The duration of the interviews ranged between 45 to 95 minutes $(M=60)$. Since logistical and travel concerns prevented in person interviews, they were conducted from a distance using the online videoconference software Skype. Synchronous modes of communication were found to offer similar benefits as face-to-face interviews, including access to non-verbal subtleties and interpersonal processes of the interactions (Hanna, 2012).

The interviews were conducted by the primary investigator who had gained interview skills through previous training in providing counseling services to athletes and general populations of college students. Initially, two pilot interviews were conducted with two of the six ineligible participants, to allow the primary investigator to ensure that the intended interview question was phrased in a way that did not reduce the scope or lead the reports of the participants' experiences. The two pilot interviews were audio-recorded and evaluated by a researcher with expertise in conducting interviews in qualitative research.

A day prior to each of the interviews, the participants received an informed consent letter outlining their rights as participants as well as the following phenomenological prompt that was used for the interview: "Looking back on your experience being coached by your father and now by your college coach, what stands out for you?'. At the beginning of the 
interviews, participants were reminded that they could disclose as little or as much as they felt comfortable with and that they could pause, reschedule, or withdraw from participation at any time. A phase of introduction and rapport building took place in order to increase the level of comfort and trust of the participants. Then, all the participants discussed their experience with coaching dual-relationship and their transition to college extensively. Unstructured probes were used for clarification and elaboration and, if needed, to address certain critical components of the coaching dual-relationship (Patton, 2002). During the entire interview, the stance of the interviewer was to use active listening skills to follow the lead of the participants without any agenda and to attend to their narratives while refraining from adopting a counseling stance. At the end of their interviews, participants were given the opportunity to elaborate on their answers and ask the interviewer any questions. All the interviews were audio recorded upon participants' consent. Off the record, the participants processed their interview experience and emotional support and normalization were provided by the interviewer. Several participants were tearful and emotional, but none of them decided to interrupt or end their interviews.

\section{Data analysis}

All interviews were transcribed verbatim (including laughs, pauses, repetitions, and non-words) from the audio recorder by the primary researcher. The lead researcher has received academic training and experience in qualitative research and was supervised by experts in qualitative research who were part of the present dissertation committee. First, each individual transcript was read and listened to carefully as a whole (Patton, 2002). Then, the parts were put in the perspective of each other and of the whole. The interviews were coded into meaning units and themes, from which psychological significance was processed by the research group members. Finally, the narratives of the coaching dual-relationship experience as co-constructed by the participants were compared across descriptions. A 